\title{
A UNIVERSIDADE E O PODER
}

Irene de Arruda Ribeiro Cardoso(1)

RESUMO: Este trabalho procura mostrar como a discussão sobre o poder na universi. dade brasileira. hoje, permanece num mesmo registro ideológico nos últimos vinte anos. Pretende identificar no chamado dis. curso da competência, nas diferentes conjunturas politicas, a construção de uma mesma oposição - qualidade x mediocridade, qualidade $\times$ politização. Ao identificar a permanência do mesmo registro ideológico, procura chamar a atenção para o fato de que pouco caminhamos nas discussões sobre o poder na universidade.

\begin{abstract}
This paper aims to show that nowadays the discussion about power in Brazilian Universities has kept to the same ideological content in the last twenty vears. It proposes to identify, in the so called discourse of competence in the different political configurations, the construction of a same opposition - quality $X$ mediocricity. quality $x$ politicization. In identifying the permanence of the same ideological content, it seeks to call attention to the fact that we have progressed very little in the discussions about power in the University.
\end{abstract}

E grande a perplexidade ao constatar que vinte anos depois os posicionamentos relativos à questão do poder na universidade brasileira estão num mesmo registro ideológico, onde os fantasmas de 68 continuam, não só presentes, mas constituem referências explícitas nos discursos enunciados. Perplexidade, ainda, ao constatar também que se as categorias esquerda e direita pareciam equacionar diferentes registros ideológicos nos anos da ditadura militar, hoje são inteiramente insuficientes como categorias explicativas, provocando mais confusão do que dando margem à identificação de posições.

Chamou a atenção a entrevista de Pierre Bourdieu publicada no Libération, transcrita pela Folha de S. Paulo, em 15 de dezembro de 1986, a propósito das manifestações estudantis contra o projeto de reforma universitária de Alain Duvaquet. Referindo-se aos anos 60, Bourdieu ressalta como naquele momento sociólogos franceses e norte-americanos anunciavam o "fim das ideologias" e foram surpreendidos pouco depois pela grande explosão de 68; em 86 constaram o fim das idéias de 68 e surgem movimentos vivos e profundamente sérios que balançam a ideologia do fim das ideologias. "Os que são partidá-

(1) Professora-assistentedoutora de Sociologia, do Departamento de Ciências Sociais da FFLCH.USP. 
rios do fim das ideologias, quer dizer, do retorno ao realismo, às realidades da empresa, da produtividade, da balança do comércio exterior, dos imperativos da política internacional da França e repudiam as esperanças ilusórias, a igualdade, fraternidade, solidariedade, falam como o pai burguês falava a seus filhos: como velhos. O fim das ideologias é o envelhecimento em escala coletiva, a resignação à ordem das coisas, essa 'sabedoria' que consiste em fazer da necessidade uma virtude. A esquerda no poder: que retrocesso! A esquerda antiinstitucional, libertária, sendo excluida do poder, os 'apparatchiks' llideres da esquerda) começaram a pregar a modernização ideológica, quer dizer, a renúncia às ilusões que os levaram ao poder. Tudo que a direita se empenhava em repetir, sem se fazer acreditar, a esquerda disse e redisse: e não conseguiu mais crédito por isso. As pessoas não acreditam mais na esquerda. " (Folha de S. Paulo, 1986)

A leitura da entrevista provocou de imediato uma sensação de grande similaridade entre o que está acontecendo na França e no Brasil (excetuando, evidentemente, a explosão das manifestações estudantis). Especialmente provocou a impressão de uma dança de significados de direita e esquerda nas conjunturas.

O confronto com o regime militar, no pós-68, consegue uma grande unanimidade nas esquerdas, na universidade, contra as cassações e prisões, contra a presença de representantes dos órgãos de segurança nas reitorias interferindo nas contratações de professores, contra o modelo de exclusão cultural construído a partir do Al-5. Unanimidade na denúncia do abandono do ensino público pelo regime militar e a conseqüente implantação do modelo de privatização da universidade brasileira, com o rebaixamento do nivel de ensino provocado por esta política; na denúncia da limitação de despesas com as universidades públicas e com a educação pública de um modo geral; na denúncia das licenciaturas curtas, do apoio financeiro a certos programas de pós-graduação e de pesquisa que pareciam importantes para o desenvolvimento econômico ou militar; na denúncia da política dos governos militares de ênfase na prestação de serviços pelas universidades às empresas privadas e públicas, com o surgimento das fundações nas universidades estaduais e federais.

Relativamente à questão da estrutura de poder na universidade, o confronto se constrói basicamente em torno do processo de excessiva concentração do poder, nos seus órgãos centrais e da hipertrofia de todo o aparelho burocrático; da necessidade, portanto, de descentralização dos poderes de decisão que deveriam estar necessariamente 
mais próximos daqueles que cumprem efetivamente os objetivos fundamentais da universidade, que são realizados de fato pelos professores e alunos, auxiliados pelo corpo de funcionários. A convivência diária com os problemas de ensino e pesquisa daria a eles, e só a eles, o real conhecimento de suas necessidades. Considera-se que a universidade deve ser um órgão de funcionamento democrático, aberto à participação de seus membros, sendo necessária a garantia da justa representação de todas as categorias nos órgãos deliberativos e executivos.

Este conjunto de posicionamentos constitui o discurso unânime das esquerdas, nos anos 70, e é encampado pelas associações de docentes das universidades que começam a ser organizadas a partir de meados da década.

O discurso dissonante e então considerado de direita, pelas esquerdas, mantendo uma grande coerência desde 68, dispara críticas contundentes ao movimento de professores filiados à Associação de Docentes da Universidade de São Paulo-ADUSP. Tais críticas questionavam a representatividade e mesmo a legitimidade da Associação de Docentes, denunciavam o "populismo universitário" e definiam o que entendia por "poder legitimo na universidade" Apontavam, ainda, as semelhanças entre os movimentos universitários dos anos $60 \mathrm{e}$ os que novamente estavam se organizando na universidade. Vale a pena detalhar um pouco estas posições, na medida em que apontam para a questão do poder.

A Associação de Docentes é entendida como uma "simples associação civil" um "clube" sem qualquer representatividade, que não pode falar em nome da universidade, "sob pena de uma total subversão da ordem e da hierarquia universitárias" (O Estado de S. Paulo, editorial de 9/4/78).

O "populismo universitário" é a designação verdadeiramente apropriada para o movimento que se intitula "democratização da universidade" pois este "o que deseja, de fato, não é democratizar a instituição, isto é, tornar o acesso a ela - e à carreira universitária - unicamente dependente do mérito, criando uma verdadeira igualdade de oportunidades, mas tumultuar a ordem" Populismo sendo definido como "a política fundada no aliciamento das classes sociais de menor poder aquisitivo" transposto para a vida universitária "significaria uma política de aliciamento das categorias de menor expressão cultural, isto é, os aprendizes, os que se estão iniciando na carreira" 10 Es- 
tado de S. Paulo, editorial de 15/5/81). O poder legítimo na universidade é caracterizado pela posição de que "os membros da comunidade universitária não são aderentes, implícitos ou explícitos, de um pacto social genérico, que justificaria uma igualdade de direitos e responsabilidades no que diz respeito à gerência da instituição. A Universidade tem uma destinação específica, vinculada à conservação $e$ ao crescimento do saber, que por si só lhe dá uma característica peculiar. Professores e estudantes ocupam seus lugares, como mestres $e$ aprendizes, nos quadros das atividades-fim da instituição, enquanto os funcionários se ocupam, genericamente, das atividades-meio. E, entre os próprios professores, há os que são ainda aprendizes (. .) e os que já atingiram uma posição ensinante indiscutivel, atestada, precisamente, pela própria idéia de carreira universitária, baseada, ao menos idealmente, em competência e maturidade" O governo legítimo da universidade é aquele que atenta para o fato de que essa não é um "Estado democrático em miniatura", mas um "organismo voltado para a conservação e criação da cultura" que deve governar-se em função de "exigências culturais" - que se exprimem exatamente pela carreira docente (O Estado de S. Paulo, editorial de 9/12/80).

Resta salientar, ainda, a aproximação realizada por esse discurso, entre os anos 60 e o movimento universitário do final dos anos 70, começo dos 80. Esta aproximação tem como principal objetivo chamar a atenção dos que ainda acreditam poder salvar as instituições universitárias da barbarização que precede a instauração da ordem total e do rebaixamento provocado pela politização da universidade.

"Depois do vazio dos movimentos de 1968 - que esta folha caracterizou, como a primavera do nada - chegou-se a ter a impressão que alcançávamos a idade do fim das utopias desvairadas que, geradas no século $X \mid X$, marcaram tão tragicamente o nosso século. Entretanto, a situação é muito mais complexa; infelizmente, os anos 80, pelo menos nos paises latinos, seja nos europeus, seja nos da América, não se distanciaram o suficiente dos anos 60."

São as "mesmas diretrizes", as "mesmas grandes Centrais, hoje, como ontem, à espera de que da anarquia possa brotar a ordem total" (O Estado de S. Paulo, editoriais de $7 / 6 / 81 ; 9 / 12 / 80$ )

Este equacionamento dos discursos, que caracteriza as discussões sobre a universidade brasileira durante todo os anos 70 , quebrase de um modo explícito em 1986, com a divulgação do Relatório GERES-Grupo Executivo para a Reformulação da Educação Supe- 
rior e com o conjunto de discussões que são travadas, seja através de artigos na imprensa, seja através de documentos produzidos pela Associação Nacional de Docentes do Ensino Superior-ANDES, e por intelectuais envolvidos no debate sobre a questão universitária. De fato, essa quebra começa a explicitar-se já em 1985, quando Tancredo Neves, diante do sentimento de crise da universidade brasileira, anunciou no seu discurso de posse, lido pelo então vice-presidente José Sarney, a intenção de criar uma comissão de alto nível para estudar a situação e encaminhar propostas. Possivelmente um estudo mais aprofundado que levasse em conta não apenas o registro da documentação produzida no final dos anos 70 , início dos 80 , mas também as práticas de política universitária, no interior das associações de docentes, pudesse fazer recuar ainda no tempo, o momento dessa quebra. Outro elemento importante de inflexão, ainda, a ser pesquisado, possivelmente seja o da criação da

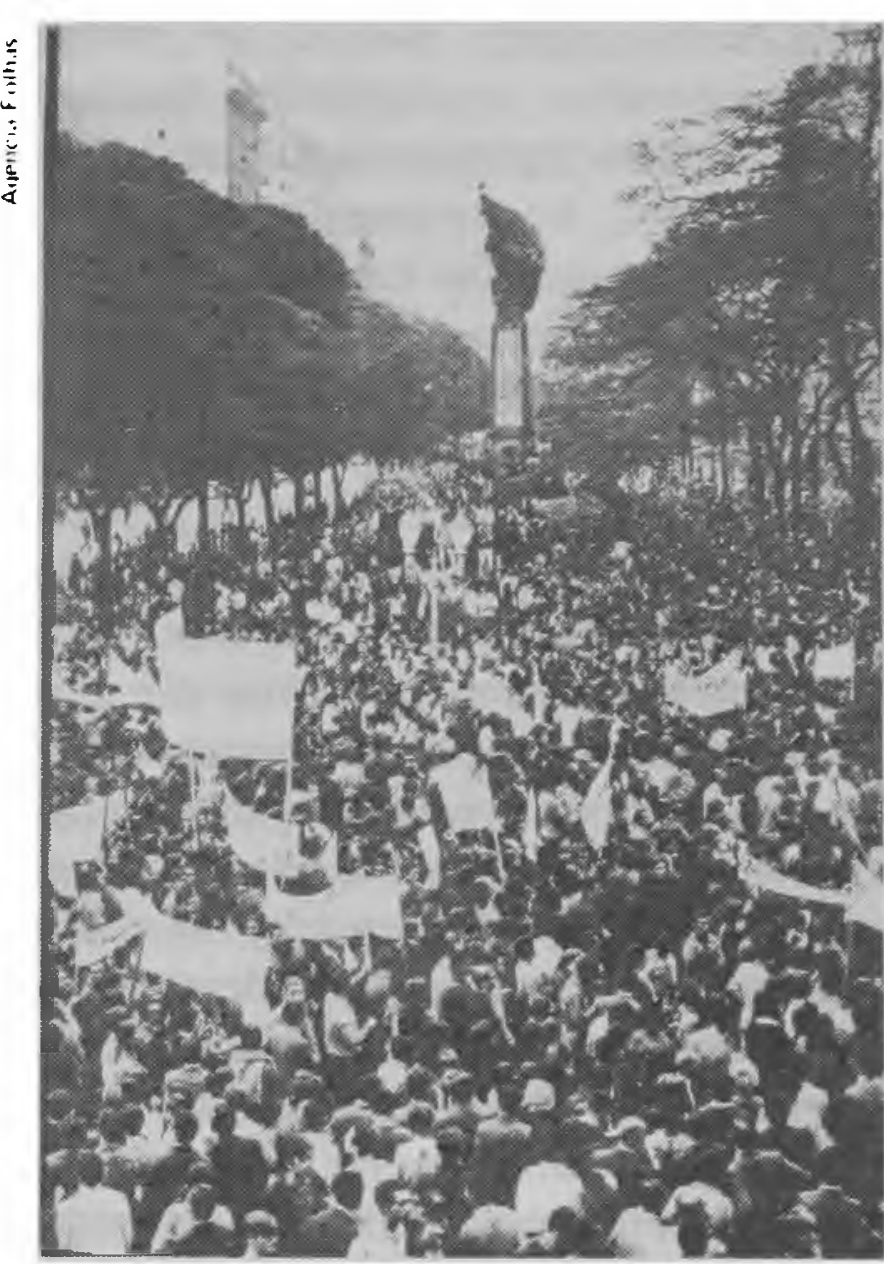

Concentração estudantil no Rio de Janeiro em 1968.

ANDES em 1981. De qualquer modo, pode-se afirmar, com segurança, que a conjuntura política iniciada com a Nova República coloca em discussão, a nível nacional, temas e questões, que permitem visualizar, com clareza, a quebra do equacionamento esọuerda-direita que marcou os anos 70.

O Relatório GERES destaca, dentre as tendências múltiplas que caracterizam o debate sobre a universidade, na transição democrática, duas, que define como:
a) "universidade alinhada"
b) "universidade do conhecimento" 
A primeira é caracterizada como aquela em que suas "atividades são meios para atingir certos objetivos politicos para a sociedade $e$ cujos paradigmas são ditados não pelo desempenho acadêmico dos agentes, mas pelo grau de compromisso político-ideológico com as forças populares"

A segunda "restaura o projeto modernizante de uma universida. de do conhecimento, baseada em paradigmas de desempenho acadêmico e científico, protegida das flutuações de interesses imediatistas, sem inviabilizar contudo sua interação com as legítimas necessidades da sociedade" Na perspectiva do Relatório, é a partir do paradigma dessa universidade do conhecimento que se organizará o sistema de avaliação, um dos pontos-chave do documento. No item relativo à gestão da universidade, o Relatório GERES afirma que " na universidade do conhecimento, as formas de gestão precisam respeitar a natureza $e$ as condições peculiares da produção e transmissão de conhecimentos", na medida em que as "funções e múltiplas atividades nela desenvolvidas se ordenam e se hierarquizam" A universidade "não é a sociedade em miniatura, mas sim uma instituição específica, em que as várias atividades e interesses a ela ligados devem subordinar-se à missão central de geração e transmissão de conhecimentos. A cidadania acadêmica, diferentemente da que se concede na sociedade global, não igualiza, ao contrário, diferencia, em função do mérito e da competência" Sem a clareza destes posicionamentos a "universidade falhará em sua missão" Poderá ser "uma universidade politizada, democrática, mas dificilmente será uma boa universidade" pois se constituirá apenas em "arma na luta política maior, instrumento utilizado pelo poder em regimes políticos de mobilização"

Foi bastante surpreendente encontrar no Relatório, exatamente no item relativo à Gestão da Universidade, um breve histórico que liga a situação presente dos movimentos de docentes e funcionários aos movimentos universitários que ocorreram nos anos 60 . Perceber que talvez os anos da ditadura militar tenham obscurecido o fato de que permanecemos num mesmo registro ideológico. A longa citação do trecho que abre o item, acima referido, elucida essa afirmação.

"Desde os fins da década de 1960, sacudiu as sociedades ocidentais amplo movimento, tanto no plano ideológico, quanto no da ação prática, de contestação das estruturas de poder existentes. Essa contestação se deu não apenas no âmbito da sociedade global, mas também, e com mais força, no interior de instituições especificas, como a Igreja, o Partido, o Sindicato e a Universidade. 
Extremaram-se, dentro da visão democrática, os componentes de origem rousseauniana, radicados na idéia de que a verdadeira demockacia deve exercer-so na forma direta, sem as mediações representativas e ressuscitaram-se posturas anarquistas. Essas idéias chegaram rapidamente a nosso Pais, onde o autoritarismo propiciou solo fértil para que germinassem com vigor. Dentro da universidade, que enfrentava prolóngada conjuntura adversa, brotaram com impeto, numa lógica reativa, os movimentos de professores $e$ servidores, empunhando, entre outras bandeiras, a da democratização interna das instituições." (Relatório GERES, 1986)

Reestabelecida a continuidade entre o final dos anos 60 e a situação presente da universidade brasileira, elaborada no próprio discurso oficial da Nova República, vai ficando cada vez mais difícil discernir o que significa esquerda e direita, categorias tão aparentemente claras nos anos da ditadura militar. A então consagrada direita do final dos anos 60 empunhava a bandeira da modernização da universidade e identificava o movimento universitário como "contestação da autoridade" e até mesmo como "guerrilha universitária" A este estado de coisas contrapunha a idéia de que a autoridade e a hierarquia universitárias devem basear-se na evidência do mérito objetivamente comprovado e na maior experiência e maturidade. Nos anos 70 , quando as esquerdas defendiam unanimemente a "democratização da universidade" a então ainda consagrada direita identificava esta posição como o "populismo universitário" também contrapondo a esta o "poder legítimo da universidade moderna" fundado na "competência e maturidade" e nas "armas da rażão" Se, no final dos anos 60, a impossibilidade do exercício do poder legítimo da universidade levaria ao caos, nos anos 70, além desta referência que continua presente, acrescenta-se a idéia de que a politização leva ao rebaixamento da universidade, pela massificação (massa de docentes, massa de funcionários, massa de estudantes).

Nos anos 80, eis que o Relatório GERES coloca em pauta a oposição "universidade alinhada-universidade do conhecimento", "universidade politizada e comprometida com as forças populares" à qual é contraposto o "projeto modernizante, baseado em paradigmas do desempenho acadêmico e científico" A impossibilidade de construção da universidade do conhecimento produzirá uma universidade "politizada e democrática" mas não uma "boa universidade" O Relatório expressa de fato um posicionamento relativo à questão do po- 
der presente nos inúmeros textos e artigos de jornal publicados, que antecedem e sucedem a sua divulgação.

A questão do poder na universidade brasileira é aí também balizada no mesmo registro expresso nas seguintes oposições:

- sábios x sabidos;

- orientação acadêmica $x$ orientação sindical;

- poder acadêmico $x$ populismo;

- competência $x$ sindicalistas e participacionistas;

- setor docente qualificado $x$ grande massa de docentes;

- competência $x$ mediocridade.

A novidade, talvez, dos anos 80 , seja a da articulação das lideranças intelectuais empenhadas na defesa da competência acadêmica que encontra apoio das sociedades científicas, proposta que se encaminha para a organização de um grupo político composto por aqueles que preocupados em ensinar e pesquisar bem, possam efetivamente propor um projeto para a universidade. Proposta que indica claramente a necessidade de tal grupo chegar ao poder, condição sine qua non para realizar o seu projeto de competência. Este posicionamento é indicativo também do debate que vem sendo travado, mais especialmente na última reunião anual da Sociedade Brasileira para o Progresso da Ciência-SBPC, sobre a despolitização da entidade, de um lado, e de outro, a consciência de uma terceira fase, atual, em que a entidade discute as questões da política científica e tecnológica, após haver passado por outras duas, identificadas como a da ciência pura e a da resistência à ditadura militar.

Restaurado o discurso da competência, restaura-se também a postura da desqualificação com que este discurso constrói as figuras da oposição. Esta passa a ser designada por termos como "esquerda radical", "baixo-clero", "populismo", assim como Ihe são conferidos atributos como "mediocridade", "imobilismo", "paranóia", "histeria" e outros. Nos anos 70 o discurso da competência da então consagrada direita, pelas esquerdas, assumia a postura da desqualificação no mesmo registro ideológico: "populismo universitário", "categorias de menor expressão cultural", "barbarização" "rebaixamento" e outros. Há referência ainda ao perigo do "caos" que caracteriza também o discurso do final dos anos 60, marcado pelas construções, da "guerrilha universitária", "permissividade"e "massificação" É curioso 


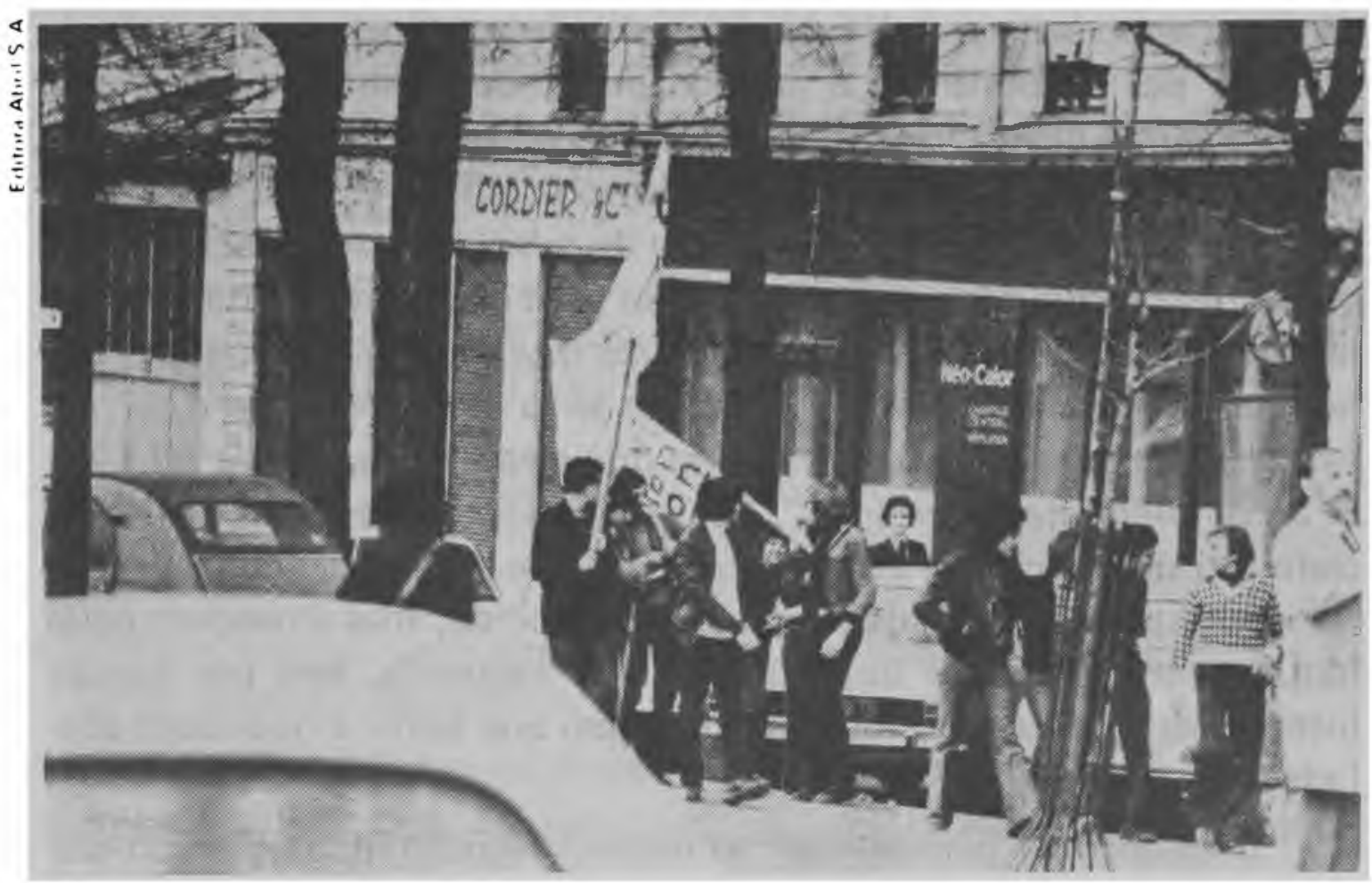

Na França, o inicio das manifestações dos estudantes, que teriam reflexo em outros paises.

lembrar, ainda, que estas construções marcaram parte do debate que se fazia na década de 30 , sobre a universidade no Brasil, através da utilização dos termos "incompetência das massas" e "rebaixamento moral"

"Ultima chance para as universidades" "perigo do imobilismo" "perigo de submersão no caos" "para salvar a universidade" são expressões reiteradas desse discurso, que aliás tem, como sempre teve, dimensão bem mais abrangente do que nosso debate nacional. Evidência disto é o polêmico livro de Laurent Schwartz: Para salvar a Universidade, de 1983 (em edição brasileira de 1984), sobre a questão do ensino e da pesquisa no sistema universitário francês. Interessa destacar especialmente as questões relativas ao exercício do poder nas universidades e as suas repercussões sobre a qualidade do ensino e da pesquisa. Trata-se de um alerta contra a ameaça de politização da universidade e mesmo do Centre National de la Recherche Scientifique-CNRS, que põe em risco não só o ensino como a própria pesquisa. $O$ receio de que especialmente os conselhos científicos das universidades acabem compostos não em função de critérios de competência, mas de critérios sindicais. Constatando que a tendência atual consiste em introduzir muito mais política do que ciência na universidade, alerta para o fato de que, em matéria de pesquisa, a competên- 
cia deve sobrelevar a política e o sindicalismo. Onde a competência se mede pela experiência e pela qualidade dos trabalhos e não pela militância sindical. Onde democracia não deve ser sinônimo de mediocridade. 0 paralelismo com a situação brasileira é, aliás, ressaltado pelo apresentador da edição brasileira do livro, Roque Spencer Maciel de Barros (1). que procura extrair lições para a vida universitária brasileira, "dadas por um grande matemático que é, ao mesmo tempo, um homem de esquerda, como pretendem sê-lo os sindicalistas e participacionistas da universidade brasileira que a estão levando, de fato, para a completa mediocrização" Outro paralelismo que pade ser destacado é o da criação da associação Qualité de la science française que, temendo que a universidade seja não defendida, mas ameaçada pelas inquietantes propostas dos sindicatos de esquerda, tem por função intervir sem concessão, todas as vezes em que sentir a qualidade abalada.

Enquanto se permanecer no mesmo registro ideológico do discurso da competência, que necessita da desqualificação do outro para a sua própria construção enquanto discurso, que se auto-identifica como o poder acadêmico legítimo e que define o que é qualidade na universidade por oposição à politização medíocre, é desalentador constatar que pouco andamos nos últimos vinte anos. Discurso que parece não se dar conta dos usos políticos do saber, ocupa grande parte dos espaços institucionais e de divulgação existentes, nos últimos dois anos. Fala, repete, insiste e produz a mesma impressão a que se refere Bourdieu, em relação à França, de que essa esquerda ("não-radical"1 diz e rediz, tudo o que a direita se empenhava em repetir sem conseguir se fazer acreditar.

(1) Membro do Grupo de Trabalho criado pelo Decreto n. 62.937/68, Ministério da Educação e Cultura, Ministério do Planejamento e Coordenação Geral, Ministério da Fazenda, - GT, que visava "estudar a reforma da Universidade brasileira, visando a sua eficiência, modernizaçāo, flexibilidade administrativa e formação de recursos humanos de alto nivel para o desenvolvimento do pals", 2-7-68. 


\section{BIBLIOGRAFIA}

ASSOCIAÇÃO de DOCENTES da UNIVERSIDADE de SÃO PAULO. Subsídios para uma política de ensino superior e pesquisa. Jornal ADUSP. (10), fev. 1985. p. 13.15.

. A Associação dos Docentes da Universidade de São Paulo e os anteprojetos de reforma do estatuto e do regimento geral da Universidade. São Paulo, ADUSP, 1978. (Texto mimeografado).

ASSOCIAÇÃO NACIONAL de DOCENTES do ENSINO SUPERIOR. Proposta das Associações de Docentes e da ANDES para a Universidade Brasileira. Cadernos ANDES. Juiz de Fora, (2), jul. 1986.

ANTUNHA, Heládio. Universidade de São Paulo: fundação e reforma. São Paulo, CRPE, Estudos e Documentos, vol. 10, 1974.

BOURDIEU, Pierre. Entrevista. Folha de S. Paulo, 15, dez. 1986. p. A-14.

CARDOSO, Irene. A Universidade da comunhão paulista. São Paulo, Cortez, 1982.

CHAUI, Marilena. Sábios e sabidos, uma discussão ociosa. Folha de S. Paulo, 22, set. 1985. Folhetim, p. 8-11.

COMISSÃO de ESTUDOS da SBPC sobre a UNIVERSIDADE. A Universidade brasileira e o projeto GERES. Jornal ADUSP, (17), mar. 1987.

CUNHA, Luiz Antonio. A Universidade Reformanda: o golpe de 1964 e a modernização do ensino superior. Niterói, Universidade Federal Fluminense, 1985. (Tese de Concurso de Professor-Titular, texto mimeografado).

DUHARCOURT Pierre. Enseignement supérieur et recherche: I'enjeu d'une transformation. La Pensée, (254), nov.-dec. 1986.

DURHAM, Eunice R. A universidade brasileira: os impasses da transformação. Ciência e Cultura. São Paulo, 38 (12): 2004-2018, dez. 1986.

A Universidade novamente em debate. Folha de S. Paulo, 21, nov. 1986. Tendências e Debates, p. 3.

A reforma da Universidade. Revista da Universidade de São Paulo. São Paulo, (4) : 9-42, mar. 1987.

Editoriais. O Estado de S. Paulo, 1978, 1980, 1981. p. 3.

FERNANDES, Florestan. Universidade Brasileira: reforma ou revolução. São Paulo, Alfa-Omega, 1975.

FRANCO, Maria Sylvia. Novos e últimos bárbaros. Folha de S. Paulo, 28, jun. 1986. Folha ilustrada, p. 64-65.

GIANNOTTI, J. A. \& CHAUI, Marilena. Entrevista. Folha de S. Paulo, 4, jan. 1987. p. A-21. 
GIANNOTTI, J.A. O mérito do poder e o poder do mérito. Folha de S. Paulo, 4 , ago. 1985. Folhetim, p. 6-8. tim, p. 4-5.

A douta incompetência. Folha de S. Paulo, 29, set. 1985. FolheUniversidade em ritmo de barbárie. São Paulo, Brasiliense, 1986.

A Universidade e a crise. Ciência e Cultura. São Paulo, 37 (7): 235-244, jul. 1985. Suplemento.

Grupo Executivo para a Reformulação da Educação Superior (GERES). Relatório. Brasília, Ministério da Educação, set. 1986. (Texto mimeografado).

La Nouvelle Vague. Libération. Paris. Numéro hors série, jan. 1987.

LEBRUN, Gèrard. Da rentabilidade. Folha de S. Paulo, 31, ago. 1986. Tendências e Debates, p. 3.

MOTA, Carlos Guilherme. O Al-5 e o modelo de exclusão cultural. O Estado de S. Paulo, 9, jul. 1978. p. 5.

SCHWARTZ, Laurent. Para salvar a Universidade. São Paulo, EDUSP 1984.

SCHWARTZMAN, Simon. O que fazer com a Universidade?. Ciência e Cu/tura, São Paulo, 37 (7): 229-234, jul. 1985. Suplemento.

- Última chance para as universidades. Folha de S. Paulo, 19, out. 1986. Tendências e Debates, p. 3.

TOURAINE, Alain. A situação atual; a ordem em questão; os movimentos sociais paralisados; a crise do ensino. In: TOURAINE, A. Cartas a uma jovem socióloga. Rio de Janeiro, Paz e Terra, 1976.

. O fim das universidades: projeto para uma nova instituição. In: TOURAINE, A. Cartas a uma jovem socióloga. Rio de Janeiro, Paz e Terra, 1976.

\section{FICHA CATALOGRÁFICA}

CARDOSO, I.A.R. A Universidade e o poder. Revista da Universidade de São Paulo. São Paulo, (6) : 59-70, jul./set. 1987. 